-Communication-

\title{
Electrocatalysis of Modified Copper Electrodes for
}

\section{Formaldehyde Oxidation}

\author{
Masao Matsuoka*, Shoichiro Watanabe, Yukio Fukumoto and Chiaki Iwakura
}

Received November 13, 1989 ; Accepted December 15, 1989

\section{INTRODUCTION}

Anodic oxidation of formaldehyde ( $\mathrm{HCHO}$ ) on noble metals and their alloys has extensively been studied in relation to electroless plating and fuel cells(1-5). The electrocatalysis by ad-atoms on noble metals was also examined widely so as to develop new functional electrode materials $(6,7)$. Among the IB metals, copper is very interesting electrode material because of its low cost, but its electrocatalytic activity is not high enough to be applied for fuel cells $(1,3)$. In addition, hydrogen ad-atoms liberated by the cleavage of $\mathrm{C}-\mathrm{H}$ bond escape from the copper surface as a gas by the recombination reaction; the overall HCHO oxidation is confirmed to be one-electron transfer process. In order to overcome these disadvantages, copper electrodes were usually modified by noble metals such as Pt, Pd and Au. The modified copper electrodes being developed in this work enable the two-electron oxidation of HCHO through the electrochemical oxidation of intermediate hydrogen ad-atoms. The evidence of two-electron transfer in HCHO oxidation and high electrocatalytic activity of the modified copper electrodes will be reported here.

\section{EXPERIMENTAL}

The working electrode was prepared by electrodeposition of copper onto a Pt wire $\left(0.1 \mathrm{~cm}^{2}\right.$ ) from the conventional acid type sulfate bath. The thickness of the copper layer was controlled to be $4.44 \mu \mathrm{m}$. The copper electrode was modified by foreign metal by using a dilute solution of noble metal salts as shown in Table 1. The amount of the foreign metals deposited on the copper surface was controlled by the immersion time and determined by the atomic absorption spectroscopy. The electrochemical measurement was carried out at $40{ }^{\circ} \mathrm{C}$ by the use of double jacketed

Table 1 Composition of displacement bath used for modification of $\mathrm{Cu}$ electrode

\begin{tabular}{llr}
\hline Au Bath & $1.020 \mathrm{mM} \mathrm{KAu}(\mathrm{CN})_{4}$ & $108 \mathrm{mM} \mathrm{KCN}$ \\
Pd Bath & $0.564 \mathrm{mM} \mathrm{PdCl} 2$ & $96 \mathrm{mM} \mathrm{HCl}$ \\
Pt Bath & $0.244 \mathrm{mM} \mathrm{H} 2 \mathrm{PtCl}_{6}$ & $30 \mathrm{mM} \mathrm{HCl}$ \\
\hline
\end{tabular}

H-type glass cell. Anodic oxidation current as a measure of catalytic activity of modified copper electrodes was measured in a solution of $0.5 \mathrm{M} \mathrm{KOH}$ and $0.1 \mathrm{M}$ HCHO by the use of a potential sweep method with a rate of $25 \mathrm{mV} / \mathrm{s}$. The potential was measured against a saturated calomel electrode (SCE) via a LugginHaber capillary. The volume of liberated hydrogen gas due to the HCHO oxidation was measured by the conventional gas burette. The number of electrons involved in the anodic oxidation of $\mathrm{HCHO}$ was determined at a constant potential from the relationship between the amount of hydrogen gas evolved and the quantity of electricity measured by the conventional coulometer.

\section{RESUULTS ÁND DISCUSSION}

The typical voltammograms for HCHO oxidation are shown in Fig.1. The peak current for HCHO oxidation was remarkably increased by the modification of copper electrodes with the foreign metals. The anodic oxidation of HCHO on the modified copper electrodes proceeded at a high reaction rate even in a fairly negative potential region where HCHO oxidation never commenced on the corresponding bulk metals used for modification. The electrocatalytic activity

Department of Applied Chemistry, University of Osaka Prefecture, 4-804 Mozu-Umemachi, Sakai, Osaka 591, Japan

Key Words: HCHO Oxidation, Modified Copper Electrode, Electrocatalysis 


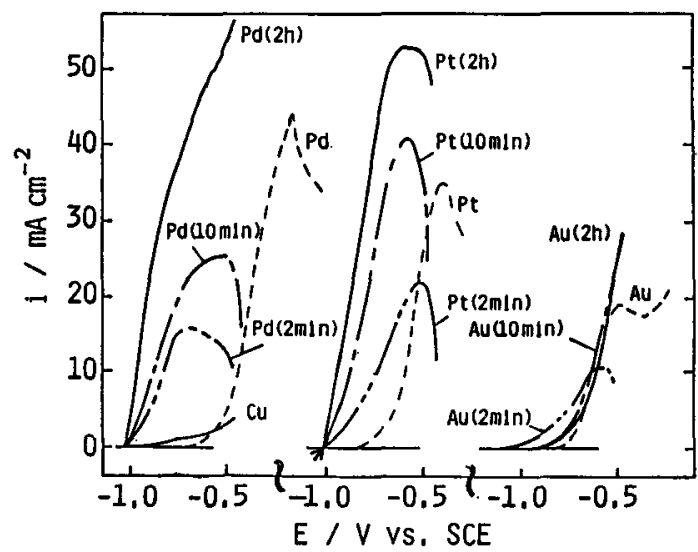

Fig.1 Typical voltammograms for HCHO oxidation on foreign bulk metal and modified copper electrodes.

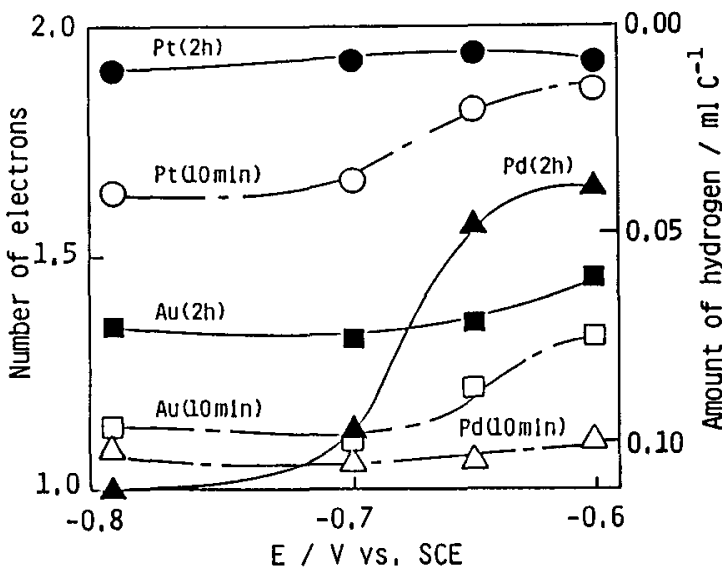

Fig. 2 Potential dependence of number of electrons and amount of hydrogen gas involved in HCHO oxidation.

increased with an increase in the amount of foreign metals up to a limiting value. These facts indicate that the foreign metals deposited by displacement reaction have superior electrocatalytic activity for HCHO oxidation. The relative electrocatalytic activity was found to increase in the order of $\mathrm{Au}<$ Pd $<$ Pt.

The number of electrons and the amount of hydrogen gas involved in the anodic oxidation of HCHO are shown in Fig.2, as a function of the potential of the modified copper electrodes. The overall reaction of HCHO oxidation could be represented by the equation [1] or [2], depending on the electrocatalytic nature of the electrode material $(1,4,5)$.

$\mathrm{HCHO}+3 \mathrm{OH}^{-}=\mathrm{HCOO}^{-}+2 \mathrm{H}_{2} \mathrm{O}+2 \mathrm{e}$

$\mathrm{HCHO}+2 \mathrm{OH}^{-}=\mathrm{HCOO}^{-}+\mathrm{H}_{2} \mathrm{O}+1 / 2 \mathrm{H}_{2}+\mathrm{e}---[2]$

On the $\mathrm{Pt}(2 \mathrm{~h})-\mathrm{Cu}$ electrode, the HCHO oxidation proceeds via two-electron transfer process as indicated by eq.[1], then hydrogen evolution was little observed in the whole potential range examined. In the case of Pt(10min)-Cu electrode, however, the contribution of the reaction [2] increased at potentials more negative than $-0.7 \mathrm{~V}$. The same was valid for the copper electrode modified by palladium, although the two-electron oxidation of HCHO was limited in a potential region of $-0.6 \mathrm{~V}$ to $-0.7 \mathrm{~V}$. The two-electron oxidation of HCHO was also observed for the copper electrode modified by gold, but the contribution of the two-electron oxidation was fairly small compared to the former two metals.

In conclusion, it was confirmed that the electrocatalytic activity and reaction scheme for HCHO oxidation depend on the kind and the amount of foreign metals used. Acceleration of HCHO oxidation will be associated with electrocatalysis induced by modified foreign metals having a specific surface electronic state which is different from that of the corresponding bulk metals. Among the foreign metals examined, the copper electrode modified by platinum having a thickness of $215 \AA$ is the most promising electrode material for the fuel cell application, as the HCHO oxidation proceeds at a high reaction rate via two-electron transfer process.

\section{REFERENCES}

1) J.E.A.M. Van Den Meerakker, J. Appl. Electrochem., 11, 387, 395 (1981).

2) P.Bindra, J.Roldan, J. Electrochem. Soc., 132, 2581 (1985).

3) M.Enyo, J. Electroanal. Chem., 186, 155 (1985).

4) M.Beltowska-Brzezinska, J.Heitbaum, J. Electroanal. Chem., 183, 167 (1985).

5) M.Beltowska-Brzezinska, Electrochim. Acta, 30, 1193 (1985).

6) R.R.Adżí, M.L.Avramov-Ivic, J. Electroanal. Chem., 134, 177 (1982).

7) M.Watanabe, Y.Furuuchi, S.Motoo, J. Electroanal. Chem., 191, 367 (1985). 